Introduction Work-related disease is a global health and safety challenge that is thought to cause over 2 million deaths worldwide annually. In addition to this, around 160 million people worldwide are estimated to become sick every year from a range of occupational exposures. This does not only affect adults, because 168 million of the world's children are child labourers, half of whom work in hazardous conditions. Dedication to the prevention of occupational disease motivated the creation of the non-profit organisation Workplace Health Without Borders (WHWB). The UK Branch of WHWB was formed in 2016.

Methods WHWB members volunteer their time to offer training, mentoring and technical assistance to develop capacity for preventing occupational disease around the world. Examples include: training, mentoring, projects to prevent exposure to silica dust in agate workers and stone-crushers in India, and in brick plant workers in Nepal, Pakistan and Tanzania. In agate silica exposure reduction, low cost engineering controls using locally available materials are being considered.

Result Practical approaches for the reduction of exposures are necessary; examples will be demonstrated where simple extraction systems and other hygiene measures have been introduced in very challenging workplace exposures. One example of this is the use of locally purchased and built extraction fans for the reduction of agate silica dust exposures in India which have resulted in a 40\%-50\% reduction in silica dust levels in some cases.

Discussion It is hoped that through education, training, mentoring and raising public awareness that improvements can be made in hazardous workplace exposures across the world. Much can be achieved remotely through online training but more effort and support is required. WHWB-UK is in the early stages of helping with this but with additional funds and support much more can be achieved.

\section{6d WHOCC AND ICOH: LEVERAGING COLLABORATIONS}

${ }^{1} \mathrm{~L}$ Nickels, ${ }^{2} \mathrm{CMCA}$ Nogueira, ${ }^{3} \mathrm{DM}$ Zalk, ${ }^{4}$ I Ivanov*. ${ }^{1}$ National Institute for Occupational Safety and Health (NIOSH), Washington DC, USA; ${ }^{2}$ University of Pretoria, Faculty of Health Sciences, Pretoria, South Africa; ${ }^{3}$ Lawrence Livermore National Laboratory (LLNL), Livermore, California, USA; ${ }^{4}$ World Health Organisation (WHO), Geneva, $\mathrm{CH}$

\subsection{6/oemed-2018-ICOHabstracts.670}

Introduction Global network members of WHO Collaborating Centres for Occupational Health (CCs) assist WHO in implementing the World Health Assembly Resolution 60.26: the Global Plan of Action on Workers' Health, (GPA) 2008-2017. Current activities align with workplan objectives for 20122017. Risk assessment, management, control and prevention of noncommunicable diseases (NCDs) are one of seven priority objectives. CCs include 50 centres of excellence in occupational health and three international partners including $\mathrm{ICOH}$. Development and delivery of training and intervention strategies for identification, prevention, and management of occupational risk factors are the best path forward to achieving sustainability and improving conditions within informal and high risk sectors.

Methods WHOCCs conducted a review of CC contributions toward WHO Secretariat in implementing the GPA under the 2006-2012 workplan. Quantitative self-administered questionnaires collected information on outputs from projects conducted by CCs. Qualitative surveys asked semi-structured questions about views, opinions and ideas regarding CCs.

Result Project leaders from 46 CCs in 28 countries (including $\mathrm{ICOH})$ responded to the quantitative survey. Of 202 responses, $78.7 \%$ produced a product and $70.5 \%$ indicated another $\mathrm{CC} / \mathrm{NGO}$ had product participation. Primary product audiences were health professionals, academic researchers, and employers. Products available by weblink or in pdf format will be made accessible through the GeoLibrary. CCs also conducted 143 training courses and materials were available for over $75 \%$ of trainings; 25 CCs responded to the qualitative survey. Key themes emerging from data analysis highlighted CCs' strengths, advantages to other networks, external constraints, areas for improvement, new ways of working, utilisation of CC contributions, collaboration among the CCs, and their WHO affiliation.

Discussion WHO and ICOH are major organisations whose work contributes to protecting workers globally. By leveraging collaboration, each brings important perspective and expertise with shared commitments to healthy and safe workplaces. The 2006-2012 review reflected the contributions and reach of these partnerships.

\section{6e QUALITATIVE STRATEGIES TO SIMPLIFY WORK-RELATED RISK REDUCTION}

DM Zalk. Lawrence Livermore National Laboratory (LLNL), Livermore, California, USA

\subsection{6/oemed-2018-ICOHabstracts.671}

Introduction Clear and consistent communication of risk within the Occupational Safety, Health, and Hygiene (OSHH) professions is essential for achieving prevention of workrelated diseases. This risk communication must be simplified. It must speak to workers directly, assisting them in identifying work-related hazards and implementing solutions. Controls that assist in preventing the most common work-related diseases are well known to OSHH professionals, yet they remain unknown to 2.5 billion workers. This results in an annual estimate of 2 million deaths from and 160 million incidences of work-related noncommunicable diseases within the global workforce, primarily in Economically Developing Countries (EDCs).

Methods Utilising fundamental Occupational Hygiene principles and Control Banding's qualitative strategy for assessing occupational risks and the selection of solutions, a Risk Level Based Management System (RLBMS) was developed. RLBMS is designed to deliver the most elusive element necessary for success; risk communication within and between OSHH professions. This qualitative occupational risk assessment and risk management strategy has been trialled across chemical, physical, and biological agents in a high regulatory enforcement environment.

Result Initial qualitative risk assessment not only standardises controls, it also prioritises where and when quantitative monitoring needs to be performed. In addition, de-confliction of multidisciplinary controls for an individual task is presented to the workers for simple, clear, and concise guidance on how to reduce risk and achieve exposure prevention on a daily basis. This simple and consistent risk communication was successful for worker understanding and implementation of controls. Further simplifying communications to colours and symbols renders it applicable in EDCs globally. 
Discussion Control Banding outcomes have been applied internationally, implemented by national institutes and university programs, and directly transferred into national regulations. RLBMS outcomes can assist in addressing the 2.5 billion workers worldwide without access to OSHH experts, providing a strategy for preventing work-related noncommunicable diseases in EDCs.

\section{HOW TO BE A BETTER FIREFIGHTER? A GUIDELINE TO IMPROVE YOUR PERFORMANCE, TAKING CARE OF YOUR PHYSICAL AND MENTAL HEALTH}

${ }^{1} \mathrm{C}$ Meneses, ${ }^{2} \mathrm{~J}$ Sierra, ${ }^{3} \mathrm{C}$ Porres, ${ }^{3} \mathrm{~L}$ Vela, ${ }^{3} \mathrm{C}$ Guzmán, ${ }^{3} \mathrm{M}$ Hernández, ${ }^{3} \mathrm{E}$ González, ${ }^{3} \mathrm{M}$ Sagastume, ${ }^{4} \mathrm{~L}$ Kurtz. ${ }^{1} A$ lumni, OSH International Master, Ludwig-MaximilliansUniversitat, Munich, Germany. Guatemalan physician; ${ }^{2}$ Chief, Voluntary Firefighters, Guatemala, Guatemala; ${ }^{3}$ San Carlos University, Guatemala, Guatemala; ${ }^{4}$ Coordinator, OSH International Master, Ludwig-Maximillians-Universitat, Munich, Germany

\subsection{6/oemed-2018-ICOHabstracts.672}

Introduction Globally, firefighting is a highly stressful, physical and mental demanding occupation. In a study carried out by the principal author, Guatemalan firefighters suffered from musculoskeletal disorders and distress, mainly because of physical unfitness, inadequate eating habits and violence exposure. A teaching intervention was planned with a component of training and the elaboration of a book, designed for Central American firefighters, with the aim of teaching firefighters how to take care of their physical and mental health. The book is already having direct impact on more than 5,000 Guatemalan firefighters.

Methods The book was planned as a teaching intervention firstly for Guatemalan firefighters and then scope was widened to Central American firefighters. It was conducted using participatory methodology with representatives of firefighters, who designed layout and wrote chapter 1. Collaboration was obtained from toxicology and nutrition experts of Universidad de San Carlos, including senior students, in writing chapters 2, 3 and 4. This University also collaborated in the printing of the first 500 copies. Collaboration was also obtained from Ludwig-Maximillians-Universitat, in writing chapters 5, 6 and 7 , as well as the final revision and layout.

Results The book was electronically issued in 2016 using Ludwig-Maximillians-Universitat networks and hard copies were delivered to Guatemala's firefighters authorities in a formal ceremony on 2017. More than 3000 of copies are waiting to be printed at Universidad de San Carlos de Guatemala.

Conclusion This is a perfect example of a successful teaching intervention, with multicenter collaboration, including universities in Germany and in Guatemala, as well as the direct participation of the targeted population.

\section{A MULTI-DISCIPLINARY, INTER-CONTINENTAL COLLABORATION TO BUILD CAPABILITY IN OCCUPATIONAL HEALTH AMONG HEALTH CARE PROFESSIONALS}

\footnotetext{
${ }^{1}$ Inakshi Naik*, ${ }^{2}$ Ashish Mittal, ${ }^{3}$ Tor Danielson, ${ }^{4}$ Robin Nicholas, ${ }^{5}$ Mahinda Seneviratne. ${ }^{1}$ Formerly South Africa NIOH, Johannesburg, South Africa; ${ }^{2}$ Medical Consultancy ServicesOHS, New Delhi, India; ${ }^{3}$ Oslo University Hospital, Oslo, Norway; ${ }^{4}$ Robin Nicholas Communications, Santa Fe, New Mexico, USA; ${ }^{5}$ SC Occupational Health in Small Scale Enterprises and Informal Sector (SCOHSSEIS), Sydney, Australia
}

10.1136/oemed-2018-ICOHabstracts.673
Introduction The interaction between community, environment and the workplace is crucial in the provision of basic health care services in low resource countries. United Nations' Sustainable Development Goals, strategies of its agencies WHO and ILO and professional bodies such as ICOH and IALI have highlighted the need for capability building and integration in delivering the necessary services to these communities. However, health care professionals, including medical doctors and nurses undergo limited training in occupational health during their professional undergraduate education.

Methods A series of workshops for health care professionals to develop knowledge and basic skills in workplace hazard identification, assessment and control were conducted in India and Malaysia. The multi-disciplinary program involving occupational medicine, hygiene, ergonomics and hazard communication was delivered by a group of occupational health professionals from five different continents. Their time and resources were provided voluntarily at no cost for the local organisers.

Result The workshops involved interactive group work facilitated by skilled specialists sharing their international experiences, together with demonstration of case studies by local experts. This approach enabled the diverse local health care workers, especially young females, to share the challenges faced in their work and develop valuable skills that can be applied to their work.

Discussion The success of these workshops has inspired the volunteers to explore the potential for developing a more sustainable 'academy' for capability building in basic occupational health. This model for a social enterprise in low resource countries through collaborating at international level will be presented and discussed.

\section{ARE WE SHIFTING EXPOSURE TO CHEMICAL AGENTS TO WAREHOUSE WORKERS?}

S Verpaele*. Becoh Vzw, Zwijnaarde, Belgium

\subsection{6/oemed-2018-ICOHabstracts.674}

European legislation related to exposure to chemical agents is becoming stricter. REACH and CLP have ensured that more agents are classified as dangerous and there are also more agents end up on authorisation and restricted lists. It is clear that the industry has to deal with this and exposure to chemicals is considered to be under control. The last few years the warehouse workers are worrying more and more about exposure to chemical agents. Deadly accidents with fumigated containers was the trigger but should we worry about that or should we be more aware about chronic exposure to a soup of chemicals? In several countries procedures for measuring sea fright containers are introduced. They are mainly based on non- or semi-selective methods and focus on 16 specific chemical agents and total VOC.

A study in different warehouses showed some remarkable results. Less than $1 \%$ of the total inbound flow was actual fumigated and this was even not deliberately. A shift in personal exposure was seen when having measuring campaigns in winter and in summer. In winter there is more background exposure and in summer the peak exposure when opening a container was higher. Investigation of the procedures that are introduced in several European countries is showing that the need for a proper risk assessment is needed before a safe unloading process can be made. The defined group of 16 chemical agents and the total VOC is far from what is needed to asses workers exposure. 